\title{
Strategic Leadership for Education Reform: Lessons From the Statewide Systemic Initiatives Program
}

Daniel Heck

Iris Weiss

Follow this and additional works at: https://repository.upenn.edu/cpre_policybriefs

Part of the Curriculum and Instruction Commons, Educational Assessment, Evaluation, and Research Commons, Educational Methods Commons, Education Policy Commons, Elementary and Middle and Secondary Education Administration Commons, Elementary Education and Teaching Commons, Science and Mathematics Education Commons, and the Secondary Education and Teaching Commons

\section{Recommended Citation}

Heck, Daniel and Weiss, Iris. (2005). Strategic Leadership for Education Reform: Lessons From the Statewide Systemic Initiatives Program. CPRE Policy Briefs.

Retrieved from https://repository.upenn.edu/cpre_policybriefs/30

View on the CPRE website.

This paper is posted at ScholarlyCommons. https://repository.upenn.edu/cpre_policybriefs/30

For more information, please contact repository@pobox.upenn.edu. 


\title{
Strategic Leadership for Education Reform: Lessons From the Statewide Systemic Initiatives Program
}

\begin{abstract}
In 1990, the National Science Foundation (NSF) created the Statewide Systemic Initiative Program. The solicitation issued by the Directorate for Science and Engineering Education sought proposals "for projects intended to broaden the impact, accelerate the pace, and increase the effectiveness of improvements in science, mathematics, and engineering education in both $\mathrm{K}-12$ and post-secondary levels"(NSF, 1990, p. 1).

Projects funded as Statewide Systemic Initiatives (SSIs) were to align various parts of the system to produce comprehensive, coordinated, and sustained change. Curriculum learning goals; content, instructional materials, and practice; assessment; teacher recruitment and preparation; and professional development of teachers, administrators, and others - all were to come under the umbrella of systemic reform, as were other parts of the system that affected "ways of doing business": organizational structure and decision making, allocation of resources, articulation within the system, and accountability. SSIs were also to involve an array of stakeholders in reform efforts - scientists and mathematicians, business and community representatives, local school system decision makers, and leaders of parent and communitybased organizations. This CPRE Policy Brief looks at some of the lessons from the SSI experience gleaned from a Horizon Research, Inc. (HRI) study of NSF's Statewide Systemic Initiative Program.
\end{abstract}

The systemic approach was intended to address two perceived shortcomings of past reform efforts. First, some analysts argue that education reform targeting isolated components of a system, even when successful, have been short-lived, primarily because pressures within the system quickly prompt a return to the status quo (e.g., Berman \& McLaughlin, 1978; Fullan, 2001; Smith \& O'Day, 1991). Second, more sophisticated efforts toward education reform - ones that address multiple components of the system have often been tied to the vision and leadership of a single individual or source of funding. With the departure of the critical individual or the loss of the particular source of funding, some researchers suggest that reform within an education system will not endure (e.g., Wiles, 1993).

\section{Disciplines}

Curriculum and Instruction | Educational Assessment, Evaluation, and Research | Educational Methods | Education Policy | Elementary and Middle and Secondary Education Administration | Elementary Education and Teaching I Science and Mathematics Education I Secondary Education and Teaching

\section{Comments}

View on the CPRE website. 


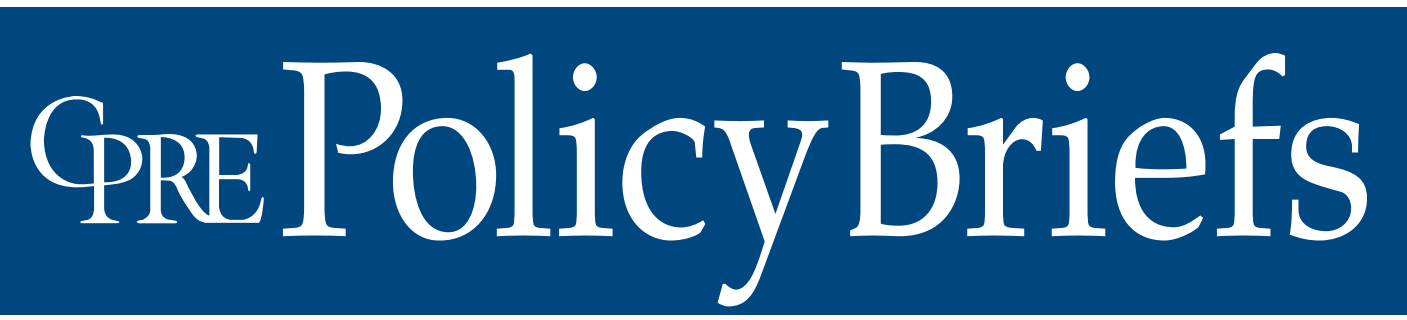

Reporting on Issues and Research in Education Policy and Finance

\section{Strategic Leadership for Education Reform: Lessons From the Statewide Systemic Initiatives Program}

By Daniel J. Heck and Iris R. Weiss

\section{Why Systemic Reform?}

In 1990, the National Science Foundation (NSF) created the Statewide Systemic Initiative Program. The solicitation issued by the Directorate for Science and Engineering Education sought proposals "for projects intended to broaden the impact, accelerate the pace, and increase the effectiveness of improvements in science, mathematics, and engineering education in both K-12 and post-secondary levels"(NSF, 1990, p. 1).

Projects funded as Statewide Systemic Initiatives (SSIs) were to align various parts of the system to produce comprehensive, coordinated, and sustained change. Curriculum learning goals; content, instructional materials, and practice; assessment; teacher recruitment and preparation; and professional development of teachers, administrators, and others - all were to come under the umbrella of systemic reform, as were other parts of the system that affected "ways of doing business": organizational structure and decision making, allocation of resources, articulation within the system, and accountability. SSIs were also to involve an array of stakeholders in reform efforts - scientists and mathematicians, business and community representatives, local school system decision makers, and leaders of parent and community-based organizations. This CPRE Policy Brief looks at some of the lessons from the SSI experience gleaned from a Horizon Research, Inc. (HRI) study of NSF's Statewide Systemic Initiative Program ${ }^{1}$

${ }^{1}$ For a fuller discussion of the results, see Heck, Weiss, Boyd, Howard, \& Supovitz (2003).
The systemic approach was intended to address two perceived shortcomings of past reform efforts. First, some analysts argue that education reform targeting isolated components of a system, even when successful, have been short-lived, primarily because pressures within the system quickly prompt a return to the status quo (e.g., Berman \& McLaughlin, 1978; Fullan, 2001; Smith \& O'Day, 1991). Second, more sophisticated efforts toward education reform - ones that address multiple components of the system - have often been tied to the vision and leadership of a single individual or source of funding. With the departure of the critical individual or the loss of the particular source of funding, some researchers suggest that reform within an education system will not endure (e.g., Wiles, 1993).

The expectation was that SSIs would design and implement reform efforts that moved beyond a single component of the system and beyond the vision of a single leader. A clear and widely shared vision would target and link multiple aspects of the system in a coordinated fashion to support deep and lasting change. SSIs would also need to devise ways to scale up interventions, develop new leaders and stable sources of funding, and tend to the politics of undertaking large-scale education reform. Much of this work was new territory for those charged with managing the SSIs. How would the principal investigators (PIs) of SSIs and others build consensus, "system" synergy and capacity, leadership, and the prospects for longevity? What can others engaged in
January 2005

RB-41

Graduate School of

Education

University of

Pennsylvania

\section{Consortium for Policy Research in Education}

University of Pennsylvania

Harvard University

Stanford University

University

of Michigan

University of Wisconsin-Madison 
large-scale reform efforts learn from these experiences? The HRI study explored the strategies used to accomplish those goals.

\section{Studying "Strategic-ness"}

During the period 1991-1998, NSF funded 26 SSIs in amounts up to $\$ 2$ million per year for five years; four of these initiatives were terminated early, while eight received funding for a second five-year phase. The HRI study of the SSIs pursued the "thinking" behind these systemic efforts - how and why they were designed, implemented, and evaluated in the ways that they were. SSI leaders and documents served as the primary data sources. ${ }^{2}$

We designed the study specifically to explore the notion of "strategic leadership." Our framework for examining this concept was informed by the literature on leadership for systems change and sustainable development in an array of fields, including education, business, nonprofit organizations, agriculture, ecology, and national development. Many parallels were evident in the fundamental principles underlying how leadership for systems change is conceived across these fields, for example, in the areas of infrastructure development, capacity building, and equity. The literature offered perspectives that were helpful in considering what aspects to investigate and how to interpret our data about the thinking behind the SSIs (e.g., Dovers, 1990; Farrell \& Hart, 1998; Goldsmith, 1996; Hickson, Butler, Cray, Mallory, \& Wilson, 1989; Koteen, 1989; Niu, Lu, \& Khan, 1993).

We paid particular attention to three criteria of strategic leadership: (a) leaders' understanding of what the SSI had the capacity to

\footnotetext{
2 This study was funded at the same time as several other research studies involving the SSIs. To maximize learning, while minimizing burden on the projects, we tried to reduce overlap as much as possible consistent with our study goals. We reviewed documents (proposals, progress reports, and evaluation reports) from 21 of the 26 SSIs, excluding the four that were discontinued midway because of insufficient progress and the one that declined to participate, and focused new data collection on 13 SSIs, some in greater depth than others. Interviews were conducted with as few as five and as many as seven leaders in each of six SSIs (Arkansas, Maine, Michigan, Nebraska, Puerto Rico, and Vermont), and with one to three leaders in each of seven SSIs (Connecticut, Delaware, Georgia, Ohio, New Jersey, South Carolina, and Texas).
}

do well and how it could be used to leverage change within the system, (b) leaders' understanding of the context in which the SSI operated, and (c) the "fit" between directions pursued by SSI leaders and the contextual conditions they were trying to change (Goldsmith, 1996). Our interpretations relied especially on theorists' conceptions of strategic thinking toward broad and sustainable change, including the extent to which leaders provided direction, prioritized the use of resources, anticipated and coped with uncertainty, and maintained an objective basis for quality control and evaluation of progress (Goldsmith, 1996; Koteen, 1989; Shrivastava, 1985).

Earlier studies of the SSIs had highlighted a critical duality in how leaders thought about the initiatives. For example, proceedings from a conference of SSI leaders noted that "Systemic reform is as much a political enterprise as it is a technical one" (Horizon Research, Inc., Inverness Research Associates, \& Westat, Inc., 1994, p. vi). Similarly, in the overall evaluation of the SSI program, Zucker and colleagues (1995) wrote "the difficulty of systemic reform stems from the fact that it presents both technical and political challenges. Technically, it requires tackling the toughest problems in a complex system of education. . . . Politically, systemic reform requires garnering professional and public support for the change agenda" (p. 47). The political work of systemic reform also required leaders to understand, work within, work around, and ultimately influence key policies that provide guidance and incentives at multiple levels in the system.

\section{Making Strategic Choices}

The HRI study sought to understand which aspects of the system leaders viewed as critical to change and why, and to understand how they acted accordingly. In designing and implementing their initiatives, SSI leaders made many choices - about target audiences, interventions, and so on. Not surprisingly, approaches to design and implementation reflected differences in the background, experience, and underlying thinking of SSI leaders. The choices were many. In addition to identifying targets for change, SSI leaders had to consider how best to allocate resources and sequence activities for maxi- 
mum benefit. Since many projects worked directly with districts, schools, and teachers, but none could do extensive work with all, SSI leaders had to make choices that they reasoned would have the best payoff. SSIs also had to balance short- and long-term objectives, especially in light of the goal of sustaining both the benefits of the reform and the reform process itself. In our study, we looked at the ways in which SSI leaders addressed short-term objectives to provide clear benefits and high visibility, even as they simultaneously pursued long-term goals for deep, structural change in the education system.

SSI leaders had other important trade-offs to consider. Striking the appropriate balance between centralized guidance and local decision making posed challenges, particularly in light of the fact that the context and history of the state often exerted considerable influence in this area. The theoretical basis for systemic education reform (Clune, 1993; Smith \& O'Day, 1991) provided some direction on this trade-off, but leaders also had to consider how much centralized guidance districts and schools expected or would tolerate, how much capacity for local decision making existed and whether it was likely to be aligned with the reform vision, and how quality control over interventions and policy implementation would occur at the local level.

The HRI study also looked at the internal and external forces that influenced leaders' thinking. For example, what were the complementary or conflicting interests of the internal SSI leadership, and how did these influence the rationale for the SSI design? Externally, SSI leaders had to consider the interests and tolerance for reform of diverse constituencies, and ensure that proposed changes met the perceived needs of different groups and benefited the education system as a whole. Whose attention, interest, and support did the SSIs attempt to cultivate? How did leaders take into account the acceptability of the proposed reforms to the public and professional stakeholders? A rational or public choice model, derived from contemporary political theories (Heywood, 1999), provided a useful interpretive lens for under- standing this aspect of the SSIs (despite the well-founded criticisms of these models that many decisions made about public services are based on incomplete information and ignore long-term consequences). Finally, we examined the extent to which SSI leaders developed and implemented a plan not simply to "scale up" a set of reform interventions to reach more teachers, classrooms, and schools, but also to "go to scale" so that the guidance, incentives, and culture of the system were transformed to support ongoing reform (Elmore, 1996).

As we came to understand it, strategic leadership requires a deep understanding of the system one is trying to change. Strategic leaders know who has power and influence. They recognize that virtually every decision has trade-offs, and they deliberately weigh the advantages and disadvantages of alternative courses of action. They use available resources efficiently and effectively, and are opportunistic in leveraging additional resources. Strategic leaders create and take advantage of opportunities for increasing the depth and coherence of reform, and are explicit about what aspects of reform are critical to long-term success. They are able to keep in mind the long-range vision and "big picture" of system reform, even as they make the myriad of day-to-day decisions involved in their work. Finally, strategic leaders use the external funding resources as a catalyst to set in motion other forces that can produce change in the system as a whole.

The HRI study was grounded in an understanding that the SSIs were intended to create substantial and enduring reform in education policy, administration and management, support services, and the teaching and learning of mathematics and science. The following lessons learned from these endeavors elaborate on some of the key findings of our study. The lessons reflect the successes, struggles, and experiences of those involved in the SSIs. We believe these lessons can provide some guidance to others who lead, oversee, provide assistance to, evaluate, and make decisions about current and future large-scale education reform efforts. 


\section{Lessons Learned}

- Strategic reform leaders have a vision of a reformed system and how to achieve it.

A vision for effective teaching and learning is not enough to guide large-scale reform. Rather, strategic leaders possess a larger view of reform and a road map for getting there. As one PI said, "To have a vision is one thing. To be able to visualize how you are going to enact it would be something different." Typically, SSIs drew their vision of high-quality mathematics/science teaching and learning from national standards documents. In some cases, that was the extent of the vision: As long as a proposed intervention or activity was consistent with national standards, or the state's interpretation of those standards, it was deemed appropriate for the SSI. As a result, SSIs often found themselves scrambling to implement a host of interventions, but without a set of criteria for ensuring that these activities were part of a coherent plan that produced system-wide change.

In contrast, strategic leaders articulated a vision that went beyond national standards documents. Some recognized the importance of this viewpoint from the outset. Others came to realize over time that simply sponsoring a myriad of standards-aligned activities was insufficient for producing the kind of long-term, system-wide impact desired. Their vision included a view of the kind of system that would support high-quality mathematics and science instruction, and a plan to reform the system accordingly. One SSI leader summed up the frustration of convening existing projects to involve them in the initiative without first developing this level of understanding:

It wasn't a unified effort of how we could come together to solve a problem, [but rather] "It's our little thing and that's all we have to do and we're not really involved in the bigger problem." .. . Because of that initial mistake, it was a battle from then on in. .. . The way that the proposal was written is that we got groups together on numerous occasions and we'd say, "All right, write us a little proposal of what you'd like to do" without any guidance or general sense of direction. So we just kept trying to fix that all the way through.
For strategic leaders, the vision for how the SSI could lead to reform represented a plausible process. The vision was contextsensitive, since it represented a design for moving a particular education system from its present condition, with all of its contextually dependent policies and practices, toward an envisioned future condition. Virtually all of the SSIs espoused a vision of excellent and equitable teaching and learning and had a number of ideas for reform activities. In contrast, the more strategic SSIs were able to explicitly link vision and strategies, respond to context without altering long-range goals for change, and specify how the particular activities would lead to system changes that supported excellent and equitable teaching and learning.

- Strategic leaders cultivate broad understanding and support for the reform vision at the highest levels.

Nearly every SSI established a steering committee or major board that included highly placed stakeholders in the state. The SSIs frequently involved the chief state school officer, college and university presidents, legislators, and representatives of the business community in their efforts. In interviews, several PIs talked about regular meetings with the governor's education advisor, or with the staff of key legislators, to keep them apprised of SSI activities and to keep the SSI informed of priorities and/or shifts in policy direction.

In terms of political strategizing, involving these key power brokers was imperative. In some cases, SSIs involved state-level stakeholders by strategically linking the SSI to an existing, influential group. For example, the South Carolina SSI crafted its design after a report issued from the Mathematics and Science Advisory Board (MSAB), a highly visible and broadly based group appointed by the governor and state superintendent. The SSI was sponsored by the MSAB as a new entity within the Department of Education, virtually assuring the support of key state leaders in government, higher education, business, and K-12 education. The backing of the MSAB and the state superintendent persuaded other important constituencies to support the SSI as well. 
Other SSIs tied their projects to existing reform movements initiated by key players in the education system as a way to garner the early support of influential stakeholders. Connecticut, Delaware, Michigan, Puerto Rico, Texas, and Vermont all took this approach. Even when the other initiatives were fledgling, linking the SSI to these efforts attracted the support of those driving the reforms. Governors and state superintendents again were frequently key players; business and industry leaders often voiced solid support for these reform movements as well.

The SSIs were uniquely positioned to play a convening role in unifying some of the divergent reform efforts, and strategic leaders took advantage of the possibilities this role offered. Including diverse and powerful state stakeholders yielded positive results not only for the SSIs, but also in terms of the interest and involvement of these constituencies in mathematics and science reform in general. Leaders in Maine and Michigan recalled that

[We] were bringing groups of people together that had never been together before, and talking about what was important about math and science education in Maine for all students, and where we were and what could be done, and there was just such enormous leverage in that.

The [Michigan] SSI provided a way to convene people, which hadn't been happening. There were all these pieces out there, but no entity to convene the players. So they got people together and got them talking in the same ways and the vision emerged from that work.

Some SSIs designed specific interventions to respond to the interests of key stakeholders as a way to engage them more fully in the reform. Michigan, for example, expanded a component targeting pre-service education because of the input of influential participants in the SSI. Maine appointed key business leaders to head its community outreach and systemic planning components. Connecticut crafted its plan specifically to respond to the interests of key stakeholders, expanding efforts in pre-service education as Michigan did, and seeking specific ways to engage stakeholders as Maine did. In Connecticut, these changes were prompted by the state's early commitment to use the SSI as part of a 12-year plan for reform in mathematics and science education. The PI reflected that

Some people said, "You know, we're never going to get people to stick around for 12 years." Well, no, [unless] they have a piece that they can play, not necessarily money that they get, and they can begin to see that we as a state are making movements toward our combined goals. People have all kinds of longevity.

To ensure that equity goals retained their prominence in the SSIs, some leaders strategically chose to include representatives of traditionally underrepresented groups in the highest levels of SSI management and operations. The Delaware SSI, for example, made a point to involve not only scientists, mathematicians, science and mathematics educators, and administrators from Delaware State University, but also representatives from community organizations serving historically underrepresented children, such as the Boys Club of Delaware and Big Brothers/Big Sisters. Similarly, the Georgia SSI engaged an ethnically diverse leadership team, and sought to establish reform centers around the state housed in universities serving specific regions, including some serving primarily minority populations.

- Strategic leaders cultivate the commitment of school and district leadership to the reform vision and activities.

Concurrent trends in most states toward centralized policy guidance on the one hand, and decentralized decision making to respond to policies on the other hand, had implications for cultivating broad understanding and support for the SSI vision. It meant that SSIs needed a presence at both the state and district levels. Much of the work of the SSIs, however, focused on engaging the more powerful, state-level constituents who were well positioned to influence policies and practices around mathematics and science education. In fact, SSIs often neglected administrators at the school and district levels - stakeholders whom many SSI leaders 
found to be more crucial than they had originally anticipated. For example, in Nebraska one of the SSI PIs recalled that the regional partnerships and scaling-up efforts went "well beyond the boundaries of the grant" in districts where the superintendent and principals demonstrated a solid commitment to the reform. One leader recalled:

Very early there was a lot of focus on building the capacity of teachers, not only to teach well but also to lead the charge, if you will. One of the mistakes in those early days is we didn't recognize how important the role of formal leadership was, and in many cases we created some high-powered teachers ready to lead in their schools, and their principals or superintendents weren't on board at all. I think we learned from that, but it was an issue early on.

The experiences of the SSIs suggest several opportunities to cultivate the will and commitment of local leaders to support reform. For example, local committees often make decisions on adopting instructional materials that play a key role in defining content and pedagogy in the classroom. Ensuring an SSI presence on these committees increased the likelihood of establishing criteria and processes for selecting high-quality materials aligned with the reform vision. Similarly, principals and other local leaders evaluate teachers and make decisions about the nature and extent of teacher professional development. Several SSIs claimed successes in changing the views of effective professional development among local decision makers and saw these changes as representative of a significant and lasting accomplishment. An SSI leader in Arkansas highlighted this accomplishment:

I think what the SSI did was it showed administrators that you didn't fix the problem with a one-day math workshop. . . . I think we educated them here in the SSI [that] that's what the research said about changing student improvement, that it's a multi-year process, that it has various components. I think that the thing that the SSI did that no report could ever reflect is that it educated administrators about what meaningful staff development would be.
Assuming that individuals and organizations would operate on the basis of rational choices (Heywood, 1999) that served their own "enlightened self-interest," strategic SSI leaders sought mutually beneficial solutions with local constituencies. For example, a leader of the Vermont SSI described how the initiative repositioned itself to help school leaders fulfill policy requirements that were called for by the state. By responding to local needs through its own work, the SSI was able to heighten awareness of, and commitment to, mathematics and science education reform:

[The new legislative act] set up expectations for schools that were different from what had been. One was that schools would start using data in more serious ways, that schools would examine their student performance data in the context of other data and create an annual action plan to focus professional development, resource allocation, energy, etc. That's made a huge difference. What we've had to do as an organization is to become responsive to the action plans. If schools have decided where they're going to put their emphasis and spend their time in professional development, we need to be part of helping them get what they need. So we spend a lot more time helping people do data analysis, translating the data into action plans, and then implementing those plans. That has fundamentally changed the way we work.

The changing nature of the responsibilities of school and district administrators, especially in the areas of data-informed decision making and accountability, provided opportunities for SSIs to influence local practices. As in Vermont, administrators throughout the United States are increasingly being required to collect, analyze, report, and use data in their decisions and actions. Many SSIs found themselves in strong positions to work with administrators to develop systems and capacities for these new responsibilities, and consequently to introduce a systemic view of management in many localities. 
- Strategic reform leaders use interventions to translate vision into practice.

Just as "actions speak louder than words," the interventions of a reform can communicate what the vision is all about. A mission statement that seeks to communicate the overall vision and direction of reform may do so with a limited audience. In contrast, interventions are there for the broader public eye to take in. They can put a face to reform. Operationalizing the reform vision through interventions is a way to demonstrate commitment to ideals and to show how that commitment translates into real efforts and activities to change the system.

Most SSIs were able to justify interventions based on need in virtually any place in the system. Strategic reform leaders, however, focused their interventions on particularly needy parts of the system and/or places where there were opportunities for considerable leverage. A leader in the New Jersey SSI explained the reasoning behind that SSI's choice of teacher professional development at the elementary and middle grades as areas of intensive initial focus, coupled with components targeting a broader scope of the system:

We felt the professional development void was greatest in the K-8 level. We only had a K-8 certificate, not even a middle school certificate. This was a pressing need. We also felt we would have some difficulty making a real impact at the high school level if we did$n^{\prime}$ t have impact first at the K-8 level. We also felt that elementary and middle schools would be more receptive because they didn't have entrenched departmentalization.

Many SSIs stressed the critical role of teachers in reform through a large investment in professional development, attending to teachers' knowledge and skills as necessary for substantive changes in teaching and learning. This approach built credibility among key constituents but sometimes revealed a more limited vision as discussed above - one focused solely on improved teaching and learning in mathematics and science. The more strategic leaders also planned for other kinds of interventions and activities directed toward broader constituencies - administrators, business, uni- versities, and communities - and used these interventions to demonstrate commitment to system-wide change.

- Strategic reform leaders recognize the benefits of starting small, refining activities as needed, and providing evidence that interventions lead to the desired outcomes.

SSI leaders learned the value of starting out with a manageable scope and scale. In cases where the interventions required more capacity or resources than the SSI could apply on a large scale, or in cases where professional or public support was mixed, starting small helped ensure that reform activities could be implemented as planned, with adequate staff and resources to work out the kinks and gather evidence of impact. Sometimes this meant a less than linear path for the SSIs. For example, a leader in the Texas SSI explained why the initiative engaged in some direct work with districts, even though the reform plan ultimately called for work through intermediary organizations, such as regional education service providers:

[We believed that] if you teach the standards and you teach them well, as they were designed, you will see high levels of performance on the test. That influenced us to work in some districts to make sure it happens, because just working through intermediaries, we've got quality control issues. And so we've tried to work directly in some districts ... to learn what it takes to make that happen.

In particular, strategic SSI leaders recognized the benefits of monitoring and evaluating interventions. Those who established data systems could track quality and impact, and use the information to improve interventions over the course of the SSI. Strategic leaders also used this evidence to demonstrate that the interventions were producing the desired results, and to secure support for expanding their efforts. For example, the Ohio SSI prepared a "Pocket Panorama" with bar graphs showing a narrowing of performance gaps between White and minority students, based on the SSI's administration of a test comprised of NAEP released items and linked to the SSI interventions. The results showing an impact on student understand- 


\section{Policy Briefs}

ing were distributed to key individuals in the state legislature, and greatly increased policymakers' interest in the SSI. Said a PI in Ohio:

We began collecting student data . . . and began our public relations campaign with those "Pocket Panoramas." They went out to every legislator and every superintendent. We had to build a constituency. . . . You know, to keep funding you have to show them kids are learning.

Similarly, the Puerto Rico SSI spent considerable resources developing, administering, scoring, and analyzing pre-post student assessments as the initiative scaled up its efforts. According to the PI, "it was money well spent" for demonstrating impact and gaining support for reform. The data showed that the interventions not only produced positive results in the small number of "Phase I" schools where the initiative's staff provided direct services and assistance, but also in the much larger number of "Phase II" schools where the faculty and administration from Phase I schools provided the majority of services and assistance.

- Strategic reform leaders develop "system" capacity to scale up reform with quality.

SSI leaders learned that many kinds of capacity are needed to implement and sustain systemic reform: human capacity to deliver the interventions; organizational capacity to house and support reform; and leadership capacity to direct, manage, and monitor reform. Such capacities were sparse in most states when the SSIs began. Even in small states, the SSIs initially lacked the capacity needed to reach all districts, schools, and classrooms.

Our study reinforced the view that a reform "initiative" can be a catalyst that sets a change in motion, rather than a force that produces all of the desired changes. Ultimately, interventions for large-scale reform have to expand well beyond the initiative's early participants. In addition, reform efforts require a system for quality control during scale-up to ensure that interventions have the desired impact. SSI leaders learned that scaling up too quickly made it difficult to maintain quality. On the other hand, scaling up too slowly made it impossible to have a broad impact. Strategic SSI leaders recognized the importance of developing feasible plans for scaling up within a reasonable time frame, and devised strategies for dealing with the inherent tension between the need for scale-up and the need for quality control.

The challenges in tending to this tension were abundantly evident in many SSIs. For example, quite a few of the SSIs worked to develop teacher leaders as a means of scaling up their initiatives. SSIs engaged these individuals in fairly intensive professional development and then arranged for them to provide workshops to other teachers, in some cases in teams that also included scientists or mathematicians as content experts. SSI leaders and evaluators who observed workshops and institutes provided by teacher leaders typically reported considerable variation in quality; they concluded that the level of professional development was insufficient for enabling many of the teacher leaders to provide high-quality professional development to their peers or to otherwise serve as leaders in their districts and schools.

The more strategic SSI leaders dealt with this challenge directly. For example, a leader in the Vermont SSI described how the project altered the design to provide additional support to teacher leaders:

The original model was based on a faith in the ability of professional development to enable teachers to go back and be leaders in their schools. What [the SSI] found over the first three or four years was that that was important, but it wasn't sufficient. The thought was that if we can bring teachers in to work in a leadership capacity in [the SSI] for a couple of years, get intensive experience in content, in pedagogy, in leadership, then go back to their schools, they'll have the leadership skills to move things forward.

A similar strategy was used in the Delaware SSI, where the initiative created a cadre of teachers and community members - mostly other school-based professionals - who would be available as "culture-change agents" to provide technical assistance to schools. Of course, the strategy of developing teacher leaders who could then provide direct services to a large proportion 
of teachers in the state was far less feasible in larger states, some of which had as many teachers as Vermont or Delaware had students. Several SSIs tapped into existing infrastructure, such as regional service centers, to scale up the reforms, but faced challenges in ensuring a common vision and consistently high-quality interventions. Those that built their own regional infrastructure for scaling up services faced similar challenges. As one leader commented, "Every [regional group] needed someone with vision, and only about half of them had it."

A different set of challenges arose for SSIs that adopted "model" sites as a scaling-up strategy. Several of the initiatives invested considerable resources in developing capacity for high-quality reform in a few schools or districts with the expectation that the quality of change in those sites would inspire other schools and districts to change, and would prompt the state to support similar capacitybuilding efforts on a larger scale. However, few of these SSIs were able to convince funders or legislatures to make such an investment, and efforts to expand the models could not be supported through the initiative's resources alone.

SSI leaders pointed to the benefits of building a feasible scaling-up strategy into the design from the outset. For example, the Puerto Rico SSI made its strategy for scaling up explicit from the beginning, laying out a plan to reach a sizable proportion of the schools in the Commonwealth. The design included strategies for building capacity and credibility through piloting, evaluating, revising, and expanding activities. Leaders were deliberate in their choice of reform strategies - starting small, using the school as the unit of change, and using regional centers as "test beds." Each step would lay the groundwork for the next, with reform leaders moving carefully and deliberately, building the capacity of core team members, major partners, and school staff along the way to ensure readiness for change. More typically, however, SSIs had some notion initially of how they might scale up, and devised other strategies as the initiatives unfolded.

From the HRI study, no single strategy for scaling up emerged as optimal across contexts. Rather, it was the process and consider- ations behind developing a strategy for scaling up that pointed to a level of effectiveness. SSI leaders who took into account a reasonable rate of growth, quality control, and a sustainable infrastructure characterized the more successful approaches. Lacking any one of these considerations, SSIs struggled to scale up reforms.

- Strategic leaders facilitate the development of formal policies that provide guidance and incentives for the reform vision.

One of the hallmarks of systemic reform is the focus on education policy as well as service delivery. Education policies provide guidance and incentives for districts, schools, teachers, and others. Policies also require these players to pay attention to specific aspects of teaching and learning, and to take advantage of particular services. Although SSI leaders had generally not been active players in shaping education policy previously, many took on this aspect of the work as a necessary part of their role.

SSI leaders positioned their projects to engage in policy work in various ways. For example, while some established close organizational ties to agencies that developed or influenced policies, SSIs that operated outside of formal education agencies often included individuals with policymaking influence as leaders in the initiative. For example, the Puerto Rico SSI was established as a partnership among three vital agencies in the education system of the Commonwealth - the Puerto Rico Department of Education, the governor's General Council on Education, and the Resource Center for Science and Engineering at the University of Puerto Rico. In addition, the PI had an established reputation for high-quality work in education and a position on the Council of Advisors to the governor.

The South Carolina SSI was similarly positioned to engage in policy work relevant to mathematics and science education. Closely tied to the South Carolina Department of Education through its leadership and organizational home, the SSI enjoyed strong support from the state superintendent. Given this position, it was a "natural" for SSI leaders to work on policies in mathematics and 
science education. When the focal policies in the state shifted from curriculum alignment to school improvement planning, the SSI's organizational position and high-level leadership allowed it to retool its policy focus, while keeping mathematics and science central to policy decisions.

In Michigan, the SSI was inaugurated within the state Department of Education, and included key leaders in mathematics and science education in the initiative's leadership. Because it began in a system that was perceived already to have a fairly supportive policy environment for systemic improvement, one observer said, "[The Michigan SSI] looked to see where there were gaps. For example, they chose not to focus on issues around standards because [that] was already in the works." Rather, the SSI defined its role in the policy arena as that of a critical friend, reviewing existing policies and their implications for districts and schools, and making recommendations for policies with greater "power and coherence" in mathematics and science, especially for underserved students in the state's schools and districts. Michigan SSI leaders in positions of influence would use the reviews and recommendations to leverage changes in the policy arena.

Making a valued contribution in one policy area sometimes opened doors for SSIs to play an expanded role in other policy areas. In some cases, SSIs took the lead in developing position papers, frameworks, or reviews that became important resources for subsequent policy developments in their states. These products signaled the intent of the SSI to be a player in the policy arena and demonstrated the capability of the SSI to do so. The remarks of one leader echoed the story of other SSIs:

[The SSI] made a conscious decision to be an active partner in the development of the statewide frameworks. That was very important, because they became the foundation for other work in the state. And through that process [the SSI] was able to build some real credibility for its capacity in math and science.

By monitoring education policies, SSIs could also develop an "inside track" on what was being offered to, and required of, districts and schools. Some SSI leaders took par- ticular advantage of such information to reposition their initiatives to help local administrators meet policy requirements. In the process, strategic SSI leaders were able to integrate the expertise, services, and systemic perspective of the initiative into the work of districts and schools.

- Strategic leaders avoid becoming a lightning rod for controversy.

The intent of the SSIs to reform the education system was bound to raise some skepticism, criticism, and perhaps even opposition. However, reform rests on the belief that the capacity to improve and to address persistent problems resides, or can be developed within, the existing system (Heywood, 1999). Fostering reform required the SSIs to engage with their skeptics, critics, and opponents in productive ways to build a common vision. As one SSI PI noted, "Anyone who doesn't understand that reform is a political game doesn't know anything about reform."

Some of the more strategic SSI leaders were able to establish neutral political turf to bring constituencies together. Maintaining a connection to, but a reasonable distance from, existing agencies allowed these initiatives to become conveners of a broad array of stakeholders and to build a reputation for facilitating collaborative solutions. One strategy for establishing neutral political territory was to house the SSI in an independent, nonprofit organization, as one leader in Maine described:

The importance of the SSI in Maine choosing to go to a nonprofit structure was very valuable, because it allowed that group to be flexible, to shift and change, and not necessarily be politically aligned anywhere. It is a highrisk strategy in the sense that we could be disregarded, but you aren't pigeonholed anywhere. So you can take the high road without having to get dragged down by other values ... in the particular institution.

Working with schools and classrooms required the SSIs to nurture relationships with those who translated state policies into local practices. Parents and other local stakeholders needed to come to understand, and more importantly to favor, the kind of teaching and learning that SSIs were advocating. 
In particular, an initiative devoted to equity had to find ways to bring together the traditionally powerful and the traditionally underrepresented voices in mathematics and science education.

The Texas SSI used an innovative strategy to engage leadership around the state, to maintain a high statewide profile, and to make the work of the SSI as politically inclusive and neutral as possible. Involving stakeholders in substantive reform work was one of its primary missions. The SSI committed itself to having diverse viewpoints to represent particular issues in mathematics and science education, with the SSI playing a background role to facilitate buy-in to the reform. Said one SSI leader from Texas:

We knew that if we could become the convener, we wouldn't have to be the leader, if you will, because we could facilitate and lead through facilitation and consensus building, because Texas is a very independent state and it's kind of hard to be the leader. There are too many leaders, and they're not willing to give up their power and authority, so that's the strategy we've used, and it's worked pretty well. It's worked better in math than in science; science is still a bit fragmented, but we're beginning to build a coalition. So that was part of what we were thinking about way back there. We wanted to be the convener, the consensus builder, around the state, and I think people would say that we are at this point.

Producing deep and lasting change in mathematics and science education systems required that SSIs make critical trade-offs in the ways they positioned themselves politically. Close ties to powerful agencies or individuals offered opportunities to influence policymaking, but could also pigeonhole the SSI and hamper its ability to involve a broader array of stakeholders. Further, reform leaders could not afford to ignore policies or influential constituencies, even if they were not entirely aligned with the SSI's goals. Finally, in seeking to transform mathematics and science teaching and learning, SSI leaders had to avoid getting so far "in front of the

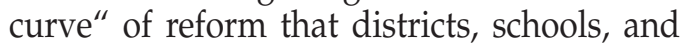
teachers could not keep up with changes.
- Strategic leaders develop the capabilities of the next generation of reform leaders.

Limited time and resources require that large-scale reform efforts "grow" new and expanded leadership - leaders who can carry the reform into the future. One Puerto Rico SSI staff member who developed into a strong leader through the SSI experience commented:

NSF's question early on made perfect sense.

"What's going to happen to the [SSI] if the plane that [the PI] is on goes down? Will the [SSI] go down too? Or are there other people who can take over?" At the beginning of the project, we said, "Well ... we're working on that." And now we can say categorically yes. We have more experience, more exposure, and more mileage now. We have grown into our roles. And the way we play our roles and our strengths, we complement each other. [The PI] allowed leadership to develop. There's good vision and good teamwork.

It is not sufficient, however, for an initiative to develop new leaders without also considering how to position those leaders to exert influence and authority. A leader of the SSI in Nebraska remarked on the consequences of failing to undertake this key task:

The legacy is really held within the people who had this experience. The legacy is not really held within the basic organizational changes. I'm afraid that with SSIs, that was the original intent - that organizations and the way of doing business would change so dramatically that the infrastructure would be there as people came and went. In reality, I think the legacy is held within the people rather than in a major lasting infrastructure. It has changed the way people do business and made them more connected, but when they leave, the legacy goes with them.

To deal with this dilemma, some SSIs arranged for positions within the existing education system where new leaders could develop their full potential and continue to support reform. For example, the Arkansas SSI managed to keep some of the SSI activities in place, despite the fact that the SSI no longer exists as an organization. In this case, toward the end of the funded period, the project director presented a plan to the Department of Education to support mathematics 
specialists throughout the state, including 15 in the existing regional service centers and 11 in the universities that had participated in the SSI. The SSI trained the mathematics specialists, and the former project director continues to coordinate their activities by meeting with the directors of these centers:

Once every six weeks or so I call a directors' meeting.... And we come together and share what we've been doing in our different regions. We have two or three state projects a year that we work on together. They all have assignments. I go visit them. I guess it's psychological; I still have the role of the director of SSI. People still say that. I just carry that on. That's kind of a perception that I just haven't allowed to let go on their part.

A number of other SSIs were able to establish organizational entities that continue to provide a base for reform leadership, such as nonprofit agencies and centers within universities. These organizations have been sustained through the commitment of state funds, fee-for-service arrangements with districts, and public and private grants, and they provide a "home" for those leaders cultivated under the SSI to continue their mission.

\section{Conclusion}

The study of strategic leadership in the SSI program provided an opportunity to examine cases of federally supported, largescale reform in mathematics and science education, even beyond the funding period. The notion of technical and political challenges was a useful analytic distinction for the study, and we suggest it can be a helpful lens for leaders of large-scale reform as they examine their plans and reflect on their work.

Many of the lessons that emerged around strategic leadership focused on political challenges rather than technical ones. Most SSI leaders were already adept at many technical aspects of reform, and they demonstrated proficiency in their proposals. By contrast, the political aspects of reform came as a surprise to many SSI leaders, and were a key area of learning. A nearly universal lesson was that attending to both technical and political aspects of large-scale reform is critical. Reform leaders ignore either at their peril.
The technical and political aspects of conducting large-scale reform are not easily separated, nor should they be. Nearly all decisions will have both technical and political considerations. Highly strategic approaches seek a balance - where neither technical concerns for quality and impact, nor political concerns for guidance and incentives, are sacrificed. Rather, these concerns become mutually reinforcing and appropriate to the broader context of the system. When compromises occur, often due to contextual factors, they reflect deep consideration of the trade-offs and do not violate the technical and political considerations needed most for advancing the reform.

Highly strategic approaches to large-scale reform are also characterized by leverage and synergy - by the leverage of policies and programs in the education context, and by a synergy that extends over time so that concurrent efforts reinforce one another and each phase of activity sets the stage for the next. For example, a strategic initiative might begin by conducting in-depth professional development and curriculum implementation, with strong quality control, in a small number of schools or districts. Such a plan affords the opportunity to reinforce the vision of teaching and learning, to test and refine interventions, to provide "existence proofs" that the interventions produce the promised results, to build capacity for scaling up the interventions, and to use results to influence policy decisions.

An alternative approach might begin with a review of state and district policies and programs to understand where there is alignment with the reform vision and where alignment is lacking. Reform leaders could use the review to identify "aligned" and "unaligned" sites, matched demographically in order to compare teaching and learning outcomes. Such a study has the potential to provide evidence that aligned policies and programs are related to the desired results, and the study could be presented to various stakeholders to cultivate support for reform. Beyond the evidence phase, aligned sites might, with the guidance of the initiative's leaders, provide assistance to other less aligned sites. The strategy might also include a process for developing local leadership and capacity to 
conduct policy and program reviews to bring more coherence to the local system.

Though overly simplified here, these designs make explicit the assumptions, progression, and interface of reform strategies, and take into consideration both short- and long-term goals and objectives. Plans for both scaling up and going to scale are included at the earliest stages. Creating such a design is no guarantee of success. However, it provides a necessary frame for guiding implementation, for dealing with unanticipated challenges and opportunities, and for informing decisions in the always unpredictable and often volatile education system.

\section{About the Authors}

Iris R. Weiss is President of Horizon Research, Inc. Her current research focuses on the implementation and impact of largescale reforms, including systemic initiatives, and the Math and Science Partnerships. Previous research has included studies of the status of mathematics and science education, including a series of national surveys of science and mathematics teachers, and observations of a large, nationally representative sample of K-12 science and mathematics classes.

Daniel J. Heck is a Senior Research Associate at Horizon Research, Inc. and a doctoral candidate in Educational Psychology at the University of Illinois at Urbana-Champaign. In addition to his current research and evaluation work on large-scale reform in science and mathematics education, he also studies teacher learning in mathematics professional development. He is completing his dissertation on the utility of multi-level modeling for answering questions about equity and excellence of student outcomes in large-scale reform.

\section{References}

Berman, P., \& McLaughlin, M. (1978). Federal programs supporting educational change: Vol. 8. Implementing and sustaining innovations. Santa Monica, CA: RAND.

Clune, W. H. (1993). Systemic educational policy: A conceptual framework. In S. H. Fuhrman (Ed.), Designing coherent education policy: Improving the system (pp. 125-140). San Francisco: Jossey-Bass.

Dovers, S. R. (1990). Sustainability in context: An Australian perspective. Environmental Management, 14(2), 297-305.

Elmore, R. F. (1996). Getting to scale with good educational practice. Harvard Educational Review, 66(1), 1-25.

Farrell, A., \& Hart, M. (1998). What does sustainability really mean? The search for useful indicators. Environment, 40(9), 4-12.

Fullan, M. (2001). The new meaning of educational change (3rd ed.). New York: Teachers College Press; Toronto, Ontario, Canada: Irwin.

Goldsmith, A. A. (1996). Strategic thinking in international development: Using management tools to see the big picture. World Development, 24(9), 1431-1439.

Heck, D. J., Weiss, I. R., Boyd, S. E., Howard, M. N., \& Supovitz, J. A. (2003). Lessons learned about designing, implementing, and evaluating statewide systemic reform. In $\mathrm{N}$. L. Webb \& I. R. Weiss (Principal Investigators), Study of the impact of the Statewide Systemic Initiatives Program (Vol. I). Madison, WI: University of Wisconsin-Madison, School of Education, Wisconsin Center for Education Research.

Heywood, A. (1999). Political theory: An introduction (2nd ed.). New York: St. Martin's Press. 


\section{Policy Briefs}

Hickson, D. J., Butler, R. J., Cray, D., Mallory, G. R., \& Wilson, D. C. (1989). Decision and organization: Processes of strategic decision making and their explanation. Public Administration, 67, 373-390.

Horizon Research, Inc., Inverness Research Associates, \& Westat, Inc. (1994). Lessons learned about the National Science Foundation's Statewide Systemic Initiative: A report on the March 1994 Wingspread Conference. Chapel Hill, NC: Horizon Research, Inc.

Koteen, J. (1989). Strategic management in public and nonprofit organizations. New York: Praeger.

National Science Foundation. (1990). Statewide systemic initiatives in science, mathematics, and engineering education: Program solicitation. Arlington, VA: Author.

Niu, W. Y., Lu, J. J., \& Khan, A. A. (1993). Spatial systems approach to sustainable development: A conceptual framework. Environmental Management, 17(2), 179-186.

Shrivastava, P. (1985). Theoretical observations on applied behavioral science. Journal of Applied Behavioral Science, 21(1), 95-107.

Smith, M., \& O'Day, J. (1991). Systemic school reform. In S. H. Fuhrman \& B. Malen (Eds.), The politics of curriculum and testing: Yearbook of the Politics of Education Association (pp. 233267). New York: Taylor and Francis.

Wiles, J. W. (1993). Promoting change in schools: Ground level practices that work. New York: Scholastic.

Zucker, A. A., Shields, P. M., Adelman, N. E., \& Powell, J. (1995). Evaluation of the National Science Foundation's Statewide Systemic Initiatives (SSI) Program: Second-year report, crosscutting themes. Menlo Park, CA: SRI International.
This Policy Brief was prepared with support from the National Science Foundation (NSF) under grant number ESR0343836. The research presented in the Brief was supported by NSF as part of a subcontract to HRI under Grant No. REC-9874171 to the Wisconsin Center for Education Research, School of Education, University of Wisconsin-Madison. The Consortium for Policy Research in Education (CPRE) is funded by the Institute of Education Sciences, United States Department of Education, under Grant No. R308A960003. Opinions expressed in this Brief are those of the authors and do not necessarily reflect the views of the National Science Foundation; the Institute of Education Sciences; the United States Department of Education; Horizon Research, Inc.; CPRE; or its institutional members. The authors wish to acknowledge the valuable assistance of Sally E. Boyd, who edited this Brief for clarity and style. 


\section{Recent CPRE Publications:}

\section{Speclal Issue: CPRE Researchers Contribute Knowledge of Assessing Teacher, Classroom, and School Effects In the Peabody Journal of Education}

CPRE researchers at the University of Wisconsin-Madison served as guest editors in the recently released issue of the Peabody Journal of Education. The researchers contributed six articles focusing generally on new directions in assessing and measuring teacher, classroom, and school effects on improvements in student academic achievement, and more specifically analyzing the criterion validity and surrounding human resources strategies of new efforts to implement performance-based teacher evaluations - the results of which in some cases are linked to new knowledge-and skills-based teacher salary schedules. A brief description of each article follows. Please e-mail cpre@gse.upenn.edu to obtain copies.

\section{Introduction to the Special Issue: Assessing Teacher, Classroom, and School Effects (Allan Odden)}

This introductory article explains the purpose and sequence of the six articles, providing background on the inter-related focus and overall conclusions drawn from the research.

Assessing Teacher, Classroom, and School Effects, Including Fiscal Effects (Allan Odden, Geoffrey Borman, and Mark Fermanich)

This article provides a general conceptual framework for the three articles to follow. The focus of this article surrounds the authors' position that too much previous research has tended to assess the effects of student, classroom, and school variables in isolation from other variables and has often used statistical techniques that ignored the nested nature of the three classes of factors. The authors identify an alternative educationally oriented framework to assess the effects of various student, classroom/teacher, and school variables on student learning.

The following articles use the developed general framework to study the criterion validity of new performance-based teacher evaluation systems, which provide one measure of teacher quality. All three places described below use some version of the teaching standards and evaluation rubrics developed by Charlotte Danielson.

The Relationship Between Teacher Performance Evaluation Scores and Student Achievement: Evidence From Cincinnati (Anthony Milanowski)

This article studies the system in Cincinnati, Ohio, the results of which were initially to be linked to a performance pay structure. Milanowski presents the results of an analysis of the relationship between teacher evaluation scores and student achievement on district and state tests in reading, mathematics, and science.

Examining the Relationship Between Teacher Evaluation and Student Assessment Results in Washoe County (Steven Kimball, Brad White, Anthony Milanowski, and Geoffrey Borman)

Kimball et al. study the system in Washoe County (Reno, Nevada), which is not linked to pay, and describe the findings from an analysis of the relationship between the scores on a standards-based evaluation system and student achievement measures.

Vaughn Elementary's Innovative Teacher Evaluation System: Are Teacher Evaluation Scores Related to Growth in Student Achievement? (H. Alix Gallagher)

This article examines the validity of a performance-based, subject-specific teacher evaluation system by analyzing the relationship between teacher evaluation scores and student achievement.

Alignment of Human Resource Practices and Teacher Performance Competency (Herbert Heneman III and Anthony Milanowski)

The authors of this article argue that human resource (HR) management practices are important components of strategies for improving student achievement in an accountability environment and that these HR systems, within which ambitious evaluation and compensation systems are managed, need to be strengthened. The authors conclude with recommendations on developing more effective HR systems.

\section{Lessons Learned About Standards-Based Teacher Evaluation Systems (Allan Odden)}

This concluding article outlines a set of "lessons learned" from the above articles, focusing largely on the lessons learned about designing, implementing, and using performance-based evaluation systems that could be linked to teacher play increases. 


\section{Nondiscrimination Statement}

The University of Pennsylvania values diversity and seeks talented students, faculty, and staff from diverse backgrounds. The University of Pennsylvania does not discriminate on the basis of race, sex, sexual orientation, religion, color, national or ethnic origin, age, disability, or status as a Vietnam era veteran or disabled veteran in the administration of educational policies, programs, or activities; admissions policies, scholarships, or loan awards; and athletic or University-administered programs or employment. Questions or complaints regarding this policy should be directed to Executive Director, Office of Affirmative Action, 1133 Blockley Hall, Philadelphia, PA 19104-6021 or 215898-6993 (Voice) or 215-898-7803 (TDD).

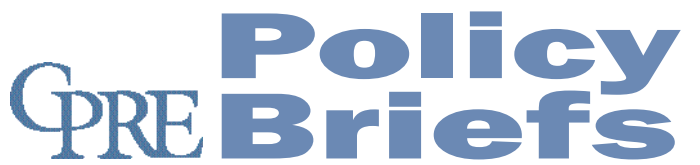

Graduate School of Education University of Pennsylvania 3440 Market Street, Suite 560

Philadelphia, PA 19104-3325

\section{About CPRE}

The Consortium for Policy Research in Education (CPRE) studies alternative approaches to education reform in order to determine how state and local policies can promote student learning. Currently, CPRE's work is focusing on accountability policies, efforts to build capacity at various levels within the education system, methods of allocating resources and compensating teachers, instructional improvement, finance, and student and teacher standards. The results of this research are shared with policymakers, educators, and other interested individuals and organizations in order to promote improvements in policy design and implementation.

CPRE unites five of the nation's leading research institutions to improve elementary and secondary education through research on policy, finance, school reform, and school governance. Members of CPRE are the University of Pennsylvania, Harvard University, Stanford University, the University of Michigan, and the University of Wisconsin-Madison.

CPRE Policy Briefs are published by CPRE. To learn more about CPRE research or publications, please call 215-573-0700 or access CPRE publications at www.cpre.org; www.wcer.wisc.edu/cpre/; or www.sii.soe.umich.edu.
NON PROFIT

U.S. POSTAGE

PAID

PERMIT NO. 2563

PHILADELPHIA, PA 